\title{
PENGARUH ISI KANDUNGAN SURAT AN-NAHL AYAT 68-69 DALAM MENINGKATKAN KREATIVITAS SISWA DI SMPN 3 CIBINONG
}

\begin{abstract}
Muhammad Divo Raja, Gunawan Ikhtiono, Ahmad Sobari
Universitas Ibn Khaldun Bogor

ABSTRACT: This study aims to determine whether there is a significant influence between the contents of the surah An-Nahl verses 68-69 in increasing student learning creativity at SMP N 3 Cibinong in the 2020-2021 academic year. This study also uses two variables, namely the contents of the surah An-Nahl verses 68-69 as the independent variable and student creativity as the dependent variable. The sample used in this study were 40 students of class VII-5 who had a pretty good creativity in learning, then class VIII-2, which amounted to 40 students, where this class was considered to be less enthusiastic in participating in teaching and learning activities and class. IX-5, amounting to 40 students who have the intelligence to think in solving problems. The technique used by researchers is random sampling. The results of this study indicate that there is no positive and significant effect between the variable content of the An-Nahl verse 68-69 surah and the variable of learning creativity calculated by Pearson Correlation. Based on the research results, it can be said that there is not a sufficient relation between the variable content of the content of the surah An-Nahl verses 68-69 and the variable of student learning creativity at SMP N 3 Cibinong. This means that there is no influence from the contents of the letter An-Nahl verses 68-69 in increasing student creativity.
\end{abstract}

Keywords: isi kandungan surat An-Nahl ayat 68-69, kreativitas siswa

\section{PENDAHULUAN}

Kreativitas merupakan istilah yang banyak digunakan baik di lingkungan sekolah maupun diluar sekolah. Pada umumnya orang menghubungkan kreativitas dengan produk-produk kreasi. Dengan kata lain, produk-produk kreasi ini merupakan hal yang penting untuk menilai kreativitas. Kreatif yaitu memiliki daya cipta atau memiliki kemampuan untuk menciptakan. Definisi Kreativitas adalah kegiatan yang mendatangkan hasil yang sifatnya baru atau belum ada sebelumnya, segar menarik, aneh dan mengejutkan, berguna dan dapat dimengerti. (Hartati, 2016)

Kegiatan kreatif mengandung perubahan arah. Keberhasilan pembelajaran khususnya dalam pembelajaran Pendidikan Agama Islam dapat dilihat dari sisi prestasi siswa dan pemahaman serta penguasaan materi yang disampaikan. Semakin tinggi tingkat pemahaman penguasaan materi, makin tinggi pula keberhasilan pembelajaran. Keberhasilan pembelajaran Pendidikan Agama Islam dapat diukur dari kemampuan siswa dalam memahami dan menerapkan berbagai konsep untuk memecahkan masalah dan pada akhirnya mampu mencapai prestasi yang baik. Setiap pembelajaran tidak lepas dari 
kesulitan-kesulitan yang dipelajarinya. Setelah mengetahui kesulitan tersebut, guru dapat mengambil manfaat untuk mengadakan perbaikan. Telah banyak cara dilakukan untuk meningkatkan prestasi siswa khususnya dalam bidang Pendidikan Agama Islam, namun kenyataannya menunjukkan nilainya tergolong rendah dibanding nilai mata pelajaran lainnya. (Mar'atus Solikah, 2019)

Setelah peneliti melakukan observasi pendahuluan, kegiatan pembelajaran yang terjadi di SMP Negeri 3 Cibinong ditemukan permasalahan yaitu sedikitnya siswa yang kreatif dalam pelajaran Pendidikan Agama Islam dan rendahnya prestasi belajar Pendidikan Agama Islam. Dilihat dari daftar nilai ulangan harian siswa SMP Negeri 3 Cibinong, masih banyaknya siswa yang mendapatkan nilai di bawah KKM , hal ini tampak bahwa rata-rata pada setiap ulangan harian hanya ada beberapa siswa saja yang tidak remedi. Berbagai upaya yang telah dilakukan oleh guru Pendidikan Agama Islam SMP Negeri 3 Cibinong untuk mengatasi peramasalahan tersebut, seperti melakukan diskusi dan tanya jawab. Namun upaya tersebut belum berhasil dikarenakan siswa yang mau bertanya dan berperan aktif dalam pelajaran Pendidikan Agama Islam hanya beberapa siswa saja, sedangkan siswa yang lain hanya sebagai pendengar dan pencatat saja bahkan ada yang tidak menggubris sama sekali. Selain itu, keterbatasannya waktu dan tuntutan untuk menyelesaikan materi selesai pada waktunya menbuat guru lebih sering menyampaikan materi pelajaran dengan metode ceramah.

Oleh karena itu peneliti mengambil judul skripsi membahas tentang kreativitas siswa terhadap pelajaran Pendidikan Agama Islam di SMP Negeri 3 Cibingong, di mana siswa SMP Negeri 3 Cibinong diharapkan dapat mencapai tujuan PAI yang pada akhirnya dapat mencapai tujuan pendidikan nasional. Dalam hal ini penulis merasa tertarik untuk melakukan penelitian dengan mengangkat judul: "Pengaruh Isi Kandungan Surat AnNahl Ayat 68-69 Dalam Meningkatkan Kreativitas Belajar Siswa Di Smp Negeri 3 Cibinong".

\section{METODOLOGI PENELITIAN}

Untuk menjawab rumusan masalah yang telah dibuat oleh peneliti, maka diperlukan suatu pendekatan penelitian (Muhyani, 2019). Adapun pendekatan penelitian yang akan digunakan dalam penelitian ini adalah pendekatan kuantitatif deskriptif. Metode penelitian yang digunakan dalam penelitian ini adalah metode survei. Menurut Rober M. Groves dalam jurnal F.C. Susila Adiyanta (2019: 700) Metode survei biasanya dilakukan dengan mengumpulkan data melalui kuesioner dan di dalamnya berisi mengenai pendapat-pendapat, kepercayaannya, sampai kepada perilaku yang telah atau sedang terjadi. Adapun tempat dan waktu penelitian yang peneliti lakukan yaitu di SMP Negeri 3 Cibinong yang beralamatkan di Jl. Raya Pemda Karadenan Kelurahan Karadenan Kecamatan Cibinong Kabupaten Bogor, Jawa Barat. Metode penelitian yang digunakan dalam penelitian ini adalah metode survei. 
Dalam penelitian kuantitatif, penelitian melakukan pengukuran terhadap keadaan suatu variabel dengan menggunakan instrumen penelitian (Sugiyono, 2016: 80). Populasi dalam penelitian ini adalah seluruh siswa di SMPN 3 Cibinong yakni terdapat 1200 siswa. Menurut (Arikunto, 2013), karena melihat subyek penelitian lebih dari 100, maka peneliti memutuskan untuk mengambil sampel sebanyak 10\% dari jumlah populasi 1.200 maka menjadi 120 sampel yaitu VII-5 (40 siswa), VIII-2 (40 siswa), IX-5 (40 siswa), dan karena kebutuhan penelitian maka peneliti membulatkan hanya menjadi 100 sampel.

Teknik analisis data merupakan cara yang digunakan untuk menguraikan keterangan-keterangan atau data yang diperoleh agar data tersebut dapat dipahami khususnya oleh peneliti dan umumnya oleh orang lain (Algifari, 2016). Peneliti menganalisis data yang terkumpul dengan menggunakan teknik analisis yang bersifat kuantitatif, dan dengan menggunakan rumus statistik product moment.

\section{HASIL PENELITIAN DAN PEMBAHASAN}

Kreativitas yang dimiliki oleh siswa SMP N 3 Cibinong dari setiap jenjangnya yaitu kelas VII, VIII dan IX adalah cukup baik sehingga dalam mengikuti pembelajaran siswa sudah bisa ikut interaktif selama proses belajar di dalam kelas baik aktif bersama guru atau teman sekelasnya. Hal ini dapat ditinjau dari kesiapan kondisi sekolah yang cukup nyaman untuk belajar, fasilitas sekolah yang cukup memadai agar proses belajar terkesan lebih menarik, juga para guru yang sudah memiliki kompetensi mengajar serta keahlian dalam menyampaikan materi dan penggunaan metode pembelajran, sehingga mempengaruhi bahkan memicu peningkatan kreativitas siswanya untuk aktif dalam mengikuti proses belajar mengajar baik di sekolah atau diluar sekolah.

Isi kandungan surat An-Nahl ayat 68-69 dalam dunia pendidikan bisa membuat beberapa ketentuan dalam pembentukan kegiatan belajar mengajar yang kreatif, aktif, inovatif juga berkesan untuk siswa, yaitu sebagai berikut :

a. Syarat yang salah satunya harus dipenuhi dalam membuat dan menjadikan kegiatan belajar menjadi lebih terkesan kreatif adalah adanya perasaan yang sangat menyenangkan secara sadar dalam pikiran dan tubuh antara siswa dan guru bahwasannya secara signifikan tertarik untuk melakukan kegiatan belajar mengajar. (Destyaningrum, 2019)

b. Jika ditinjau dari point pertama dalam klasifikasi keunikan seekor lebah maka dari itu guru yang di artikan sebagai fasilitator seorang siswa sudah selayaknya membeikan fasilitas yang nyaman, bersih dan rapih agar proses kegiatan belajar mengajarnya dapat berlangsung dengan baik juga senantiasa dapat menjaga bahkan mengembangkan fokus serta konsentrasi siswa. (As'ad, 2018)

c. Kemudian dengan terciptanya chemistry antara guru dan siswa maka yang dapat kita ambil dari point ke dua adalah kita anggap bahwa nektar adalah inti sari untuk dikonsumsi atau kita anggap sebagai informasi materi yang diberikan oleh bunga yang mana bunga ini kita umpamakan juga sebagai seorang guru dan seekor lebah adalah siswa atau peserta didik, maka harus dipastikan bahwa informasi materi 
yang disampaikan oleh guru harus sampai kepada tahap pemahaman dan peresapan dalam hati siswa sehingga siswa dapat memanfaatkan kembali apa yang sudah ia dapat pada saat belajar. (Ali Imran, 2018)

d. Dalam point ke tiga dapat kita masukkan kedalam metode pembelajaran yang sekiranya sesuai dengan keunikan dari kehidupan lebah tersebut, yaitu kedalam metode debat di mana kelompok satu dengan lainnya saling mengutarakan pendapat dan pada saat ada sesuatu yang sekiranya tidak sependapat maka dalam satu kelompok harus saling mendukung untuk mengembalikan pendapat yang lebih kuat. (Ali Imran, 2018)

e. Dan di point terakhir pada proses pembelajaran dengan metode kelompok debat kita bisa juga mengembangkan metode tersebut dengan cara memberikan variasi didalamnya yaitu dengan mengaplikasikan metode lain seperti metode kuis misalnya, dengan beberapa informasi yang telah di dapat oleh salah seorang anggota maka wajib hukumnya untuk mendiskusikan kepada kelompok lain agar semua memahami dan bisa menjawab soalan berikutnya. (As'ad, 2018)

Jadi, dapat ditarik garis besar dari semua klasifikasi tentang peri-kehidupan lebah yang berkaitan dengan dunia pendidikan khususnya dalam rangka meningkatkan kreativitas belajar siswa di mata pelajaran pendidikan agama islam adalah bahwasanya terdapat metode pembelajaran yang dapat diaplikasikan juga divariasikan sehingga menciptakan nuansa kegiatan belajar dan mengajar yang aktif, kreatif dan juga inovatif serta terjalin makna yang akan berpengaruh besar terhadap keberhasilan dalam pencapaian tujuan pembelajaran.

Untuk mengetahui sejauh mana kreativitas siswa SMP N 3 Cibinong Kabupaten Bogor dapat dilihat dari sejumlah angket yang disebarkan kepada 100 responden dengan 15 item pernyataan pada setiap variabel (X dan $Y$ ).

Dari jumlah angket yang disebarkan oleh peneliti kepada 100 responden, maka akan diperoleh uraian presentase jawaban dari setiap item yang kemudian akan diberi skor dan dijumlahkan secara total. Hasil keseluruhan dari jawaban setiap variabel yang diberikan kepada 100 responden dapat dilihat sebagai berikut:

Rekapitulasi Jawaban Angket Variabel X dan Y

\begin{tabular}{|c|c|c|c|c|c|c|c|c|c|}
\hline \multirow{3}{*}{ No } & \multicolumn{8}{|c|}{ KATEGORI JAWABAN } & \multirow{3}{*}{ JML } \\
\hline & \multicolumn{2}{|c|}{ SS } & \multicolumn{2}{|c|}{$\mathrm{S}$} & \multicolumn{2}{|c|}{ TS } & \multicolumn{2}{|c|}{ STS } & \\
\hline & $\mathrm{F}$ & $\%$ & $\mathrm{~F}$ & $\%$ & $\mathrm{~F}$ & $\%$ & $\mathrm{~F}$ & $\%$ & \\
\hline \multicolumn{10}{|c|}{ ANGKET VARIABEL $\mathrm{X}$} \\
\hline 1 & 40 & 40,0 & 47 & 47,0 & 9 & 9,0 & 4 & 4,0 & 100 \\
\hline 2 & 33 & 33,0 & 34 & 34,0 & 24 & 24,0 & 9 & 9,0 & 100 \\
\hline 3 & 33 & 33,0 & 36 & 36,0 & 19 & 19,0 & 12 & 12,0 & 100 \\
\hline 4 & 34 & 34,0 & 28 & 28,0 & 22 & 22,0 & 16 & 16,0 & 100 \\
\hline 5 & 34 & 34,0 & 28 & 28,0 & 23 & 23,0 & 15 & 15,0 & 100 \\
\hline 6 & 34 & 34,0 & 34 & 34,0 & 22 & 22,0 & 10 & 10,0 & 100 \\
\hline
\end{tabular}




\begin{tabular}{|c|c|c|c|c|c|c|c|c|c|}
\hline 7 & 32 & 32,0 & 28 & 28,0 & 18 & 18,0 & 22 & 22,0 & 100 \\
\hline 8 & 28 & 28,0 & 28 & 28,0 & 31 & 31,0 & 13 & 13,0 & 100 \\
\hline 9 & 35 & 35,0 & 27 & 27,0 & 27 & 27,0 & 11 & 11,0 & 100 \\
\hline 10 & 25 & 25,0 & 36 & 36,0 & 16 & 16,0 & 23 & 23,0 & 100 \\
\hline 11 & 31 & 31,0 & 32 & 32,0 & 25 & 25,0 & 12 & 12,0 & 100 \\
\hline 12 & 26 & 26,0 & 30 & 30,0 & 28 & 28,0 & 16 & 16,0 & 100 \\
\hline 13 & 35 & 35,0 & 30 & 30,0 & 27 & 27,0 & 8 & 8,0 & 100 \\
\hline 14 & 36 & 36,0 & 25 & 25,0 & 30 & 30,0 & 9 & 9,0 & 100 \\
\hline 15 & 38 & 38,0 & 55 & 55,0 & 5 & 5,0 & 2 & 2,0 & 100 \\
\hline \multicolumn{7}{|c|}{ ANGKET VARIABEL Y } \\
\hline 16 & 37 & 37,0 & 62 & 62,0 & 0 & 0 & 1 & 1,0 & 100 \\
\hline 17 & 37 & 37,0 & 40 & 40,0 & 4 & 4,0 & 19 & 19,0 & 100 \\
\hline 18 & 30 & 30,0 & 28 & 28,0 & 19 & 19,0 & 23 & 23,0 & 100 \\
\hline 19 & 32 & 32,0 & 35 & 35,0 & 21 & 21,0 & 12 & 12,0 & 100 \\
\hline 20 & 47 & 47,0 & 5 & 5,0 & 11 & 11,0 & 37 & 37,0 & 100 \\
\hline 21 & 29 & 29,0 & 17 & 17,0 & 19 & 19,0 & 35 & 35,0 & 100 \\
\hline 22 & 22 & 22,0 & 27 & 27,0 & 25 & 25,0 & 26 & 26,0 & 100 \\
\hline 23 & 22 & 22,0 & 32 & 32,0 & 15 & 15,0 & 31 & 31,0 & 100 \\
\hline 24 & 28 & 28,0 & 30 & 30,0 & 16 & 16,0 & 26 & 26,0 & 100 \\
\hline 25 & 10 & 10,0 & 48 & 48,0 & 14 & 14,0 & 28 & 28,0 & 100 \\
\hline 26 & 25 & 25,0 & 34 & 34,0 & 19 & 19,0 & 22 & 22,0 & 100 \\
\hline 27 & 30 & 30,0 & 28 & 28,0 & 17 & 17,0 & 25 & 25,0 & 100 \\
\hline 28 & 42 & 42,0 & 26 & 26,0 & 15 & 15,0 & 17 & 17,0 & 100 \\
\hline 29 & 40 & 40,0 & 34 & 34,0 & 11 & 11,0 & 15 & 15,0 & 100 \\
\hline 30 & 25 & 25,0 & 68 & 68,0 & 3 & 3,0 & 4 & 4,0 & 100 \\
\hline Jumlah & 950 & 950,0 & 952 & 952,0 & 585 & 585,0 & 499 & 499,0 & \\
\hline Rata- & & & & & & & & & \\
Rata & 31,67 & 31,67 & 31,73 & 31,73 & 19,50 & 19,50 & 16,63 & 16,63 & \\
\hline
\end{tabular}

Berdasarkan tabel di atas, dapat disimpulkan rekapitulasi siswa SMP N 3 Cibinong, rata-rata presentase yaitu: alternatif jawaban sangat setuju memiliki 31,67\%, alternatif jawaban setuju memiliki rata-rata $31,73 \%$, alternatif jawaban tidak setuju memiliki ratarata $19,50 \%$, dan alternatif jawaban sangat tidak setuju memiliki rata-rata 16,63\%.

Kesimpulan dari pernyataan di atas dapat diketahui bahwa jumlah terbanyak adalah alternatif dengan jumlah skor 3 yang rata-ratanya berjumlah $31,73 \%$. Sehingga dapat diketahui bahwa mayoritas siswa SMP N 3 Cibinong menjawab setuju.

Untuk memperkuat hasil data rekapan dari pertanyaan-pertanyaan pada lembar angket, maka dilakukan juga Uji Persyaratan yang didalamnya terdapat beberapa hal yang harus di ujikan kembali diantaranya yaitu ada, Uji Normalitas dan Uji Homogenitas serta Uji Hipotesis. Dalam (Muhyani, 2019) Uji Normalitas adalah sebuah uji yang dilakukan dengan tujuan untuk menilai sebaran data pada sebuah kelompok data atau variabel, apakah sebaran data tersebut berdistribusi normal ataukah tidak. Sedangkan pengujian homogenitas dilakukan untuk menguji kesamaan dari beberapa bagian sampel. Dan 
Tujuan dari Uji Hipotesis adalah untuk menetapkan suatu dasar sehingga dapat mengumpulkan bukti yang berupa data-data dalam menentukan keputusan apakah menolak atau menerima kebenaran dari pernyataan atau asumsi yang telah dibuat. Keterangan hasil dari ketiga pengujian tersebut adalah sebagai berikut:

Uji Normalitas

\begin{tabular}{|ll|r|r|}
\hline & & \multicolumn{1}{|c|}{$\mathrm{x}$} & \multicolumn{1}{c|}{$\mathrm{y}$} \\
\hline $\mathrm{N}$ & & 100 & 100 \\
Normal Parameters $^{\mathrm{a}, \mathrm{b}}$ & Mean & 43.03 & 39.58 \\
& Std. & 6.325 & 3.990 \\
& Deviation & .106 & .098 \\
Most Extreme & Absolute & .106 & .098 \\
Differences & Positive & -.096 & -.065 \\
& Negative & .106 & .098 \\
Test Statistic & & $.008^{\mathrm{c}}$ & $.020^{\mathrm{c}}$ \\
Asymp. Sig. (2-tailed) & & \\
\hline
\end{tabular}

Berdasarkan tabel 4.36 hasil dari uji Kolmogorov-Smirnov, menunjukkan bahwa nilai signifikan dari masing-masing variabel yaitu variabel isi kandungan surat An-Nahl 68-69 (X) sign 0,08 dan variabel kreativitas siswa (Y) sign 0,20 di mana nilainya lebih besar dari $a=0,05$ (Asymp. Sign $=0,08>0,05$ ), dan (Asymp. Sign $=0,20>0,05$ ), maka data tersebut terdistribusi secara normal.

Uji Homogenitas

\begin{tabular}{|l|c|c|c|c|c|}
\hline & $\begin{array}{c}\text { Sum of } \\
\text { Squares }\end{array}$ & df & $\begin{array}{c}\text { Mean } \\
\text { Square }\end{array}$ & F & Sig. \\
\cline { 2 - 6 } Between Groups & 312.205 & 24 & 13.009 & .772 & .759 \\
Within Groups & 1264.155 & 75 & 16.855 & & \\
Total & 1576.360 & 99 & & & \\
\hline
\end{tabular}

Berdasarkan tabel 4.37 di atas, maka diperoleh nilai signifikansi sebesar 0,759 lebih besar dari 0,05. Sehingga dapat disimpulkan bahwa variabel antara isi kandungan surat An-Nahl ayat 68-69 dengan kreativitas siswa adalah homogen.

Hasil Uji Hipotesis

\begin{tabular}{|c|c|c|c|c|}
\hline Model & $\mathrm{R}$ & $\mathrm{R}$ Square & $\begin{array}{c}\text { Adjusted R } \\
\text { Square }\end{array}$ & $\begin{array}{c}\text { Std. Error of } \\
\text { the Estimate }\end{array}$ \\
\hline 1 & $.253^{\mathrm{a}}$ & .064 & .054 & 3.881 \\
\hline
\end{tabular}


Berdasarkan tabel 4.38 di atas, dapat diketahui bahwa nilai $r$ hitung 0,253>0,195 maka dapat disimpulkan bahwa terdapat korelasi atau hubungan isi kandungan surat AnNahl ayat 68-69 dengan kreativitas siswa.

Dengan data yang telah diperolah dan diolah sedemikian rupa, maka penelitian yang dilakukan di SMP N 3 Cibinong kali ini dengan jumlah responden 100 siswa dan instrumen dalam penelitian ini menggunakan angket atau kuesioner dengan jumlah pernyataan 30 item, dari 30 item tersebut mayoritas siswa menjawab setuju dengan frekuensi sebesar $31,73 \%$. Kemudian dilakukan pengujian dengan alat bantu SPSS 26 dan didapat hasil validitas angket tersebut, 26 item valid dan 4 item tidak valid. Lalu dilakukan uji reliabilitas dan di dapat hasil variabel $\mathrm{X}$ sebesar 0,688 dan variabel $\mathrm{Y}$ sebesar 0,550. Hal ini berarti instrumen yang digunakan oleh peneliti dalam mengumpulkan data dapat di percaya atau reliabel sebagai alat pengumpul data. Berdasarkan uji syarat analisis data yang telah dilakukan dalam penelitian ini, maka menunjukkan bahwa data berasal dari distribusi normal dengan nilai signifikansi 0,08.

Setelah diperoleh dari hasil angket, maka dapat dilakukan perhitungan dengan menggunakan metode uji regresi linear pada SPSS 26 dan diperoleh hasilnya sebesar 0,253 . Angka 0,498 berada antara 0,20-0,399 yang termasuk lemah, sehingga peneliti dapat menarik kesimpulan isi kandungan surat An-Nahl ayat 68-69 dengan kreativitas siswa berada pada tingkat hubungan yang lemah.

Berdasarkan hasil di atas, menyatakan hubungan isi kandungan surat An-Nahl ayat 68-69 dengan kreativitas siswa di SMP N 3 Cibinong pada tingkat yang lemah, maka hipotesis nol (Ho) diterima, hal ini berarti hipotesis alternatif (Ha) ditolak, atau dengan kata lain tidak terdapat hubungan yang signifikan antara isi kandungan surat An-Nahl ayat 68-69 dalam meningkatkan kreativitas siswa.

\section{SIMPULAN}

Setelah melaksanakan observasi dan melakukan pengamatan terhadap kreativitas siswa SMP N 3 Cibinong dapat disimpulkan bahwasannya, kreativitas yang dimiliki oleh siswa adalah cukup baik sehingga dalam mengikuti pembelajaran siswa sudah bisa ikut interaktif selama proses belajar di dalam kelas baik aktif bersama guru atau teman sekelasnya.

Setelah melakukan analisis terhadap isi kandungan surat An-Nahl ayat 68-69, unsurunsur pokok pendidikan yang terkandung dalam surat An-Nahl ayat 68-69 yaitu, Rasa keterterikan dalam belajar antara guru dan siswa, Guru sebagai fasilitator, Kemampuan guru memberikan informasi, Kemampuan guru menggunakan metode pembelajaran, Kemampuan guru mengembangkan metode pembelajaran, Kemampuan siswa menghadapi masalah, Kemampuan untuk berkembang dalam belajar, Keluasan berpikir dalam belajar, Kemampuan penilaian terhadap hasil belajar dan Minat terhadap kreasi dalam belajar.

Berdasarkan penelitian, dapat disimpulkan bahwa tidak terdapat pengaruh yang signifikan antara isi kandungan surat An-Nahl ayat 68-69 dalam meningkatkan kreativitas 
siswa siswa di SMP N 3 Cibinong, dengan hasil r sebesar 0,253 yang terletak antara 0,200,399 , dan dapat dikatakan terdapat korelasi yang lemah.

\section{DAFTAR PUSTAKA}

Algifari. (2016). Mengukur Kualitas Layanan Dengan Indeks Kepuasan, Metode Important Perfomance Analysis dan Model Kano. Yogyakarta: BPFEYogyakarta.

Ali Imran, A. Z. (2018). Nilai-nilai Pendidikan Dalam Al-Qur'an (kajian surah AnNahl). Edu Riligia, 391.

Arikunto, S. (2013). Prosedur Penelitian. Jakarta: PT Rineka Cipta.

As'ad. (2018). Metode Mengajar Dalam Al-Qur'an Kajian Surat An-Nahl Ayat 125. AlIrsyad: Jurnal Pendidikan dan Konseling, 118.

Destyaningrum, A. (2019). Kecerdasan Spiritual Dalam Perspektif Al-Qur'an Surat AnNahl Ayat 78. 1.

Hartati, L. (2016). Upaya Guru PAI Dalam Mengembangkan Kreativitas Siswa. AlBahtsu, 198.

Mar'atus Solikah, C. S. (2019). Upaya Guru Dalam Mengembangkan Kreativitas Peserta Upaya Guru Dalam Mengembangkan Kreativitas Peserta. Jurnal Pendidikan Islam, 59.

Muhyani, M. (2019). Metodologi Penelitian. Bogor: Uika Press.

Sugiyono. (2016). Metode Penelitian. Bandung: Alfabeta. 